\title{
Spondilitis tuberkulosis relap pasca debridemant dan fusi
}

\author{
Roni Eka Sahputra \\ Divisi Ortopedi, Bagian Bedah, Fakultas Kedokteran Universitas Andalas
}

Korespondensi: Roni Eka Sahputra; email: roni78esahputra@gmail.com

\begin{abstract}
Abstrak
Spondilitis tuberkulosis merupakan penyakit tuberkulosis ekstrapulmonar yang sering terjadi. Insiden kasus mencapai setengah dari angka kejadian tuberkulosis muskuloskeletal. Kebanyakan spondilitis TB terjadi pada anak-anak dan dewasa muda. Angka kejadian cenderung meningkat pada negara berkembang. Vertebrae lumbal merupakan area yang sering terjadi. Gambaran destruksi diskus intervertebralis dan meluas ke korpus, kompresi medula spinalis dan anterior wedging menyebabkan deformitas kiposis dan terbentuknya gibbus. Tujuan: Melaporkan kasus spondilitis relap pasca tindakan pembedahan. Kasus: Sebuah kasus spondilitis tuberkulosis thoracolumbal junction yang relap setelah dilakukan debridement dan fusi sebelumnya pada pasien laki-laki berusia 31 tahun. Keluhan saat ini kembali merasakan nyeri di punggung bawah yang menjalar ke paha kiri disertai kelemahan kedua tungkai sejak 6 bulan terakhir. Pada pemeriksaan penunjang X-Ray dan MRI thoracolumbal ditemukan fusi corpus thoracal (Th) 10 - lumbal 1, stabilisasi dengan pedicel screw pada Th10-11, lumbal 1-2, terlihat destruksi corpus intervertebralis Th7-8. Dilakukan implant removal, circumferential debridement, dan dekompresi pada Th7-8 dan dilakukan stabilisasi di Th5, 6, 9, dan 10. Intra operatif ditemukan terbentuknya sinus yang menghasilkan pus dan masa perkejuan sepanjang Th7-9. Simpulan: Kekambuhan dipengaruhi oleh multifaktorial seperti usia, kepatuhan pengobatan, efektivitas debridement, dan status gizi.
\end{abstract}

Kata kunci: spondilitis; tuberkulosis; relap

\section{Abstract}

Tuberculous spondylitis is an extrapulmonary tuberculosis that often occurs. The incidence of cases reaches half of the incidence of musculoskeletal tuberculosis. Most TB spondylitis occurs in children and young adults. Incidence tends to increase in developing countries. The lumbar spine is a common area. The appearance of the intervertebral disc deformation and extending to the body, spinal cord compression and anterior wedging cause kyphosis deformity and the formation of gibbus. Objective: To report relapsing of tuberculous spondylitis after surgery. Case: A case of thoracolumbal junction tuberculous spondylitis that relapsed after previous debridement and fusion in a 31-year-old male patient. His complaint is pain in the lower back that radiates to the left thigh accompanied by weakness in both legs in the last 6 months. In the X-ray and MRI thoracolumbal, fusion of Th10 - L1 was found, stabilization with pedicels screw in the Th10 -11 and L 1-2, saw destruction of the 7-8 intervertebral corpus. Performed implant removal, circumferential debridement and decompression in Th 7-8 and stabilization was carried out in Th5,6,9,10. Intra-operative sinus formation is found which produces pus throughout Th7-9. Conclusion: Recurrence is influenced by multifactorial factors such as age, medication adherence, debridement effectiveness, and nutritional status.

Keywords: spondilitis; tuberculosis; relapse 


\section{PENDAHULUAN}

Spondilitis tuberkulosis merupakan penyakit tuberkulosis ekstrapulmonar yang sering terjadi. Insiden kasus mencapai setengah dari angka kejadian tuberkulosis muskuloskeletal. Kebanyakan spondilitis TB terjadi pada anak-anak dan dewasa muda. Angka kejadian cenderung meningkat pada negara berkembang. Diagnosa segera dan tata laksana yang tepat dibutuhkan untuk mencegah kerusakan neurologi permanen dan mencegah deformitas tulang belakang. Faktor predisposisi termasuk kemiskinan, kepadatan penduduk, sosial, malnutrisi, drug-abuse, diabetes melitus, terapi imunosupresif, dan HIV. ${ }^{1}$

Keterlibatan tulang belakang dihasilkan dari penyebaran hematogen $M$. tuberculosis pada pembuluh darah tulang cancellos korpus tulang belakang. Infeksi primer sering terjadi pada paru-paru dan sistem genitourinaria. Penyebaran terjadi melalui pembuluh darah arteri ataupun vena. Kuman TB kemudian akan mencapai berbagai organ di seluruh tubuh. Organ yang dituju adalah organ yang mempunyai vaskularisasi baik, misalnya otak, tulang, ginjal, dan paru sendiri, terutama apeks paru atau lobus atas paru. Bagian pada tulang belakang yang sering terserang adalah peridiskal terjadi pada 33\% kasus spondilitis TB dan dimulai dari bagian metafise tulang, dengan penyebaran melalui ligamentum longitudinal anterior terjadi sekitar 2,1\% kasus spondilitis TB. Penyakit dimulai dan menyebar dari ligamentum anterior longitudinal.
Radiologi menunjukkan adanya skaloping vertebra anterior, sentral terjadi sekitar $11,6 \%$ kasus spondilitis TB. Penyakit terbatas pada bagian tengah dari badan vertebra tunggal, sehingga dapat menyebabkan kolaps vertebra yang menghasilkan deformitas kiposis. ${ }^{1-3}$

Karakteristik spondilitis tuberkulosis adalah destruksi diskus intervertebralis dan korpus yang berdekatan, kolapsnya elemen tulang belakang, anterior wedging dan terbentuknya gibbus (deformitas yang teraba karena keterlibatan beberapa tulang belakang). Segmen thorakal dan lumbal merupakan lokasi yang sering mengalami kerusakan. Kerusakan pada umumnya terjadi pada lebih dari satu korpus dan korpus lebih sering diserang dari pada arkus posterior. . $^{1,3,4}$

Gambaran klinik berupa nyeri lokal, nyeri tekan lokal, kaku dan spasme otot, abses, gibbus, dan deformitas. Nyeri punggung gejala yang paling sering dikeluhkan. Nyeri bertambah dengan pergerakan tulang belakang, batuk dan berat badan karena kerusakan diskus dan instabilitas tulang belakang, kompresi serabut saraf atau fraktur patologi. Deformitas tulang belakang yang terjadi tergantung lokasi lesi. Kifosis terjadi karena lesi mengenai vertebra thorakal. Derajat kifosis tergantung pada jumlah vertebra yang terlibat. ${ }^{1,3,5}$

Diagnosis spondilitis tuberkulosis ditegakkan berdasarkan klinis dan pemeriksaan penunjang. Konfirmasi etiologi dengan ditemukannya bakteri tahan asam berbentuk batang pada 
spesimen biopsi. ${ }^{3}$

Penatalaksanaan spondilitis tuberkulosis masih kontroversial; beberapa penulis menganjurkan pemberian obat-obatan saja, sementara yang lainnya merekomendasikan obat-obatan dengan intervensi bedah. Dekompresi agresif, pemberian obat anti tuberkulosis selama 9-12 bulan dan stabilisasi spinal dapat memaksimalkan terjaganya fungsi neurologis. Obat-obatan anti tuberkulosis seharusnya diberikan segera. Tipe pembedahan yang bisa dilakukan adalah debridement pada segmen terinfeksi dengan atau tanpa stabilisasi tulang belakang (rekonstruksi). ${ }^{5-7}$

Prognosis spondilitis TB bervariasi tergantung dari manifestasi klinik yang terjadi. Prognosis yang buruk berhubungan dengan TB milier, dan meningitis TB, dapat terjadi sekuele antara lain: tuli, buta, paraplegi, retardasi mental, gangguan bergerak dan lain-lain. Prognosis bertambah baik bila pengobatan lebih cepat dilakukan. Mortalitas yang tinggi terjadi pada anak dengan usia kurang dari 5 tahun (30\%). Angka kekambuhan pasca tindakan pembedahan mencapai $60 \%$. Gambarannya bisa berupa tidak adanya perbaikan gejala lokal ataupun sistemik, abses, luka insisi tidak sembuh dan terbentuknya sinus. ${ }^{8}$

\section{LAPORAN KASUS}

Laki-laki, 31 tahun dengan keluhan kedua tungkai sejak 6 bulan yang lalu. Tidak ada riwayat trauma pada pasien. Pasien sudah dikenal menderita spondilitis TB pada tahun 2013 dan sudah dilakukan debridement, dekompresi dan stabilisasi pada tulang belakang segmen Th10-11 lumbal 1-2.

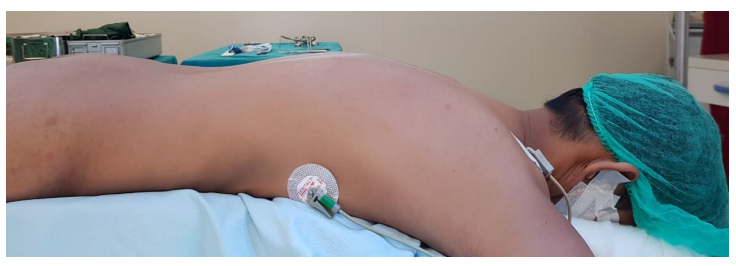

Gambar 1. Gibbus teraba pada vertebrae thorakal.

Pasien mengonsumsi Obat Anti Tuberkulosis (OAT) selama 1 bulan dan menghentikan sendiri pengobatannya dengan alasan pasien merasa sudah perbaikan. Pasien bekerja sehari-hari sebagai sopir. Pasien memiliki riwayat merokok 2-3 batang rokok sehari. Pasien memiliki status gizi baik. Tidak ada keluhan pada buang air kecil dan buang air besar. Ditemukan gibbus pada tulang belakang segmen thorakal (gambar 1).

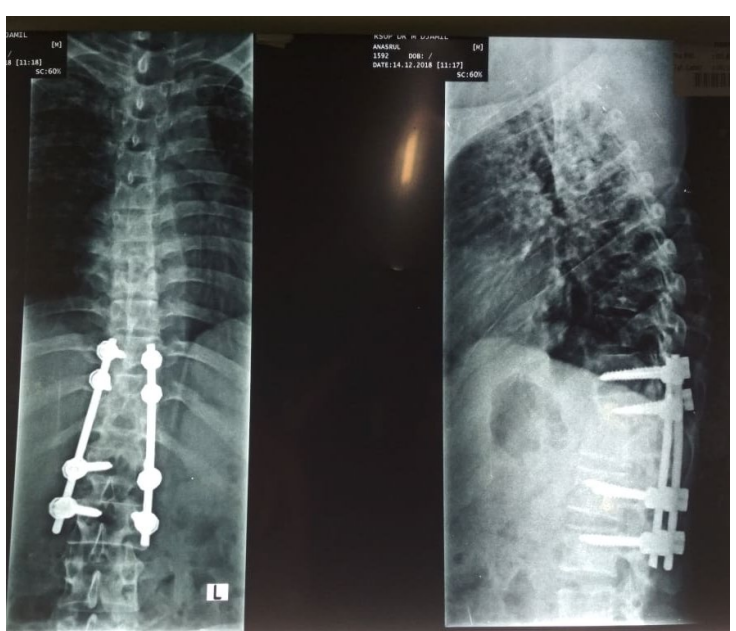

Gambar 2. X-ray Thoracolumbal (AP \& Lateral). Penyempitan diskus Th7-8 dan destruksi corpus Th8, terdapat fusi pada Th11-12 yang terfiksasi dengan 8 buah pedicel screw dan 2 rod.

Pasien mampu mengangkat kedua tungkai namun tidak bisa menahan beban yang 
diberikan. Terdapat nyeri saat dilakukan pemeriksaan pada tungkai pasien. Pada pemeriksaan foto rontgen thorakolumbal kesan terdapat penyempitan diskus thorakal (Th) 7-8 dan destruksi corpus Th8, terdapat fusi pada Th11-12 yang terfiksasi dengan 8 buah pedicel screw dan 2 rod (gambar 2).

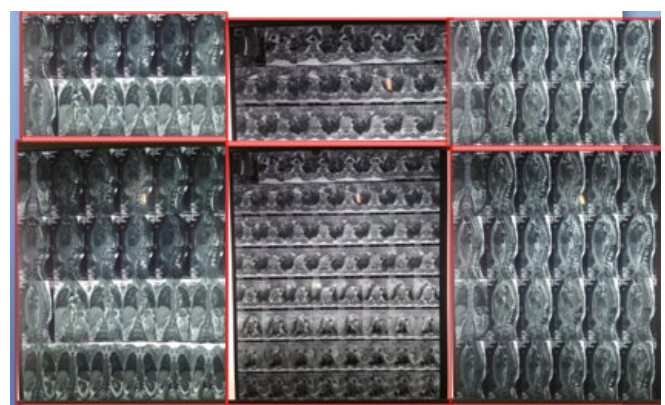

Gambar 3. MRI thoracolumbal menunjukkan destruksi corpus vertebrae Th8.

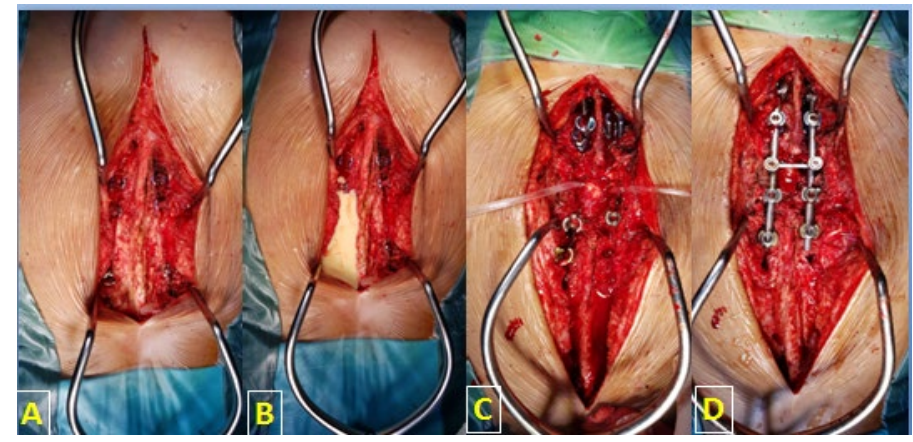

Gambar 4. Temuan Intraoperatif; A. Fusi Th 9-10; B. Temuan intraoperatif: pus dan perkejuan; C. Sirkumferensial debridemant; D. Stabilisasi Th5-6,9-10

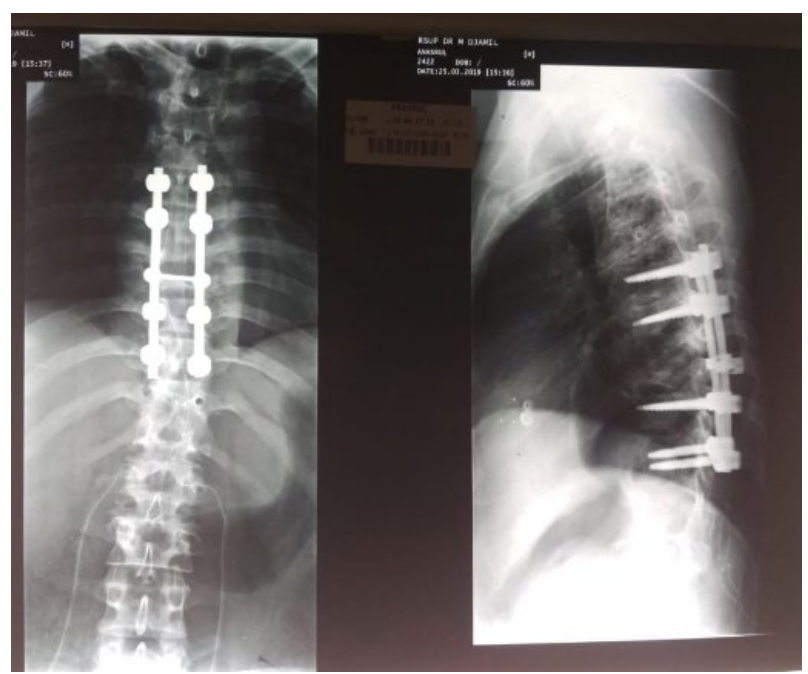

Gambar 5. X-Ray Thorakolumbal. Fiksasi Th5-6,9-10 dengan 8 pedicel screw dan 2 rod

MRI thoracolumbal menunjukkan destruksi corpus vertebra thorakal 8 (gambar 3). Pada pasien dilakukan tindakan debridement dan stabilisasi (gambar 4). Kami melepaskan implant yang sudah dipasang sebelumnya karena intraoperatif terlihat fusi yang luas dan kuat, ekspos di thorakal 7-8 keluar pus lebih kurang 100 cc dan kemudian dilakukan debridement dan ditemukan perkejuan pada Th8-9, dilakukan laminektomi dan sirkumferential dekompresi serta stabilisasi pada Th5-6,910 (gambar 5). Pasien diberikan pengobatan OAT post-operatif. 


\section{PEMBAHASAN}

Penatalaksanaan spondilitis tuberkulosis masih kontroversial; beberapa penulis menganjurkan pemberian obat-obatan saja, sementara yang lainnya merekomendasikan obat-obatan dengan intervensi bedah. Dekompresi agresif, pemberian obat anti tuberkulosis selama 9-12 bulan dan stabilisasi spinal dapat memaksimalkan terjaganya fungsi neurologis. Obat-obatan anti tuberkulosis seharusnya diberikan segera. Tipe pembedahan yang bisa dilakukan adalah debridement pada segmen terinfeksi dengan atau tanpa stabilisasi tulang belakang (rekonstruksi).

Angka kekambuhan pasca tindakan pembedahan mencapai 60\%. Gambarannya bisa berupa tidak adanya perbaikan gejala lokal ataupun sistemik, abses, luka insisi tidak sembuh dan terbentuknya sinus. Manifestasi berupa destruksi tulang $(8,8 \%)$, abses $(74,4 \%)$, dan fistula $(16,7 \%)$ pada kasus rekurensi pasca pembedahan.

Pada sebuah studi dilaporkan faktor yang berhubungan dengan kasus relap pasca pembedahan termasuk usia, jenis kelamin, resistensi OAT, debridement tidak adekuat, rekonstruksi tulang belakang, status gizi, adanya TB organ lain, segmen yang terlibat dan waktu dilakukannya intervensi bedah.

Pembedahan tanpa pemberian obat anti tuberkulosis memiliki angka rekurensi yang tinggi. Pembedahan disarankan dilakukan setelah pemberian OAT selama 4 minggu. Studi terbaru melaporkan semakin singkat jarak pembedahan dengan pemberian OAT akan meningkatkan rekurensi. Durasi OAT pasca operasi juga meningkatkan angka rekurensi jika diberikan dalam waktu lebih singkat.

Penyakit kronik, pola makan dan status kesehatan yang buruk juga meningkatkan angka rekurensi pasca pembedahan.

\section{SIMPULAN}

Penyebab rekurensi pasca pembedahan pada spondilitis tuberkulosis sangat kompleks. Dengan mengetahui dan menganalisis faktor risiko yang berhubungan dengan kejadian tuberkulosis bisa menurunkan angka kejadian rekurensi pasca pembedahan sehingga meningkatkan kualitas hidup penderita.

\section{UCAPAN TERIMA KASIH}

Terima kasih kepada dr. Septry Larissa atas bantuannya dalam penanganan pasien selama rawatan.

\section{DAFTAR PUSTAKA}

1. Garg RK, Somvanshi DS. Spinal Tuberculosis: A Review. J Spinal Cord Med. 2011; 34(5):440-454. doi: $10.1179 / 2045772311$ Y.0000000023.

2. Yang L, Liu Z. Analysis and therapeutic schedule of post operative recurrence of bone tuberculosis. J Orthop Surg Res. 2013; 8:47. doi: 10.1186/1749-799X-8-47. 
3. Rajasekaran S, Soundararajan DCR, Shetty AP, Kanna RM. Spinal Tuberculosis: Current Concepts. Global Spine J. 2018; 8(4S):96S-108S. doi: 10.1177/2192568218769053.

4. Yin XH, Liu ZK, Hao D. The reason and clinical treatment of post operative relapse of Pott's disease. Medicine. 2018; 97(39):e12471. doi: 10.1097/MD.0000000000012471.

5. Jiang $\mathrm{T}$, Zhao J, He M, Wang K, Fowdur M, Wu Y. Outcomes and Treatment of lumbosacral Spinal Tuberculosis: A Retrospective Study of 53 patients. PLOS One. 2015; 10(6):e0130185. doi: 10.1371/journal.pone.0130185.

6. Chen YH, Lin CB, Harnod T, Wu WT, Yu JC, Chen IH, et al. Treatment modalities for tuberculosis of thespine: 22 years' experience in east Taiwan. Formosan Journal of Surgery. 2013; 46(6):189-194. doi: 10.1016/j.jjs.2013.06.005.

7. Djientcheu VP, Mouafo Tambo FF, Ndougsa IS, Eloundou NJ, Kouna Tsala IN, Ngowe Ngowe M, et al. The role of surgery in the management of Pott's disease in Yaoundé: A review of 43 cases. Orthop Traumatol Surg Res. 2013; 99(4):419-23. doi: 10.1016/j.otsr.2012.12.022.

8. Wang B, Kong L, Zhu Z, Gao W, Guo H, Wang X, et al. Recurrent complex spinal tuberculosis accompanied by sinus tract formation: cause of recurrence and clinical treatment. Sci Rep. 2018; 8(1):6933. doi: 10.1038/s41598-018-25142-z. 